\title{
МОЙ УЧИТЕЛЬ, НАСТАВНИК - ФЕДОР НИКОЛАЕВИЧ МИЛЬКОВ
}

\author{
В.И. Булатов \\ Югорский государственный университет, Россия \\ Поступила в редакцию 12 января 2019 г.
}

\begin{abstract}
Аннотация: Развитие ландшафтоведения в России началось уже более века назад - с трудов В. В. Докучаева и Л.С. Берга. Накопленный к 1955 году мощный интеграционный потенциал естественных наук привел к появлению современной науки о ландшафтах, теоретические основы которой активно прорабатывались на 6-ти Всесоюзных совещаниях по вопросам ландшафтоведения (19551963 гг.). В это время формируются ландшафтно-географические школы, существующие и поныне (московская, ленинградская (питерская), воронежская, иркутская и др.). Географическое образование и практические исследования становятся невозможными без овладения теорией и методами ландшафтного анализа и синтеза, картографирования и районирования. Именно это заставило руководство Томского университета (ТГУ) с подачи кафедры географии сделать запрос в Министерство высшего образования о предоставлении места в аспирантуре на кафедре физической географии МГУ выпускнику факультета, т.е. мне, имеющему год стажа работы в должности ассистента, для целевой подготовки в области ландшафтоведения. Такое направление было получено, оставалось только появиться в столице и приступить к учебе.
\end{abstract}

Ключевые слова: Ф.Н. Мильков, ландшафтоведение.

\section{My teacher, mentor - Fyodor Nikolayevitch Milkov \\ V.I. Bulatov}

Abstract: The development of landscape science in Russia began already more than a century ago with the works of V.V. Dokuchayev and L.S. Berg. The powerful integration potential of the natural sciences, accumulated by 1955 , led to the emergence of modern landscape science, the theoretical foundations of which were actively worked out at 6 All-Union meetings on landscape science (1955-1963). At this time, landscape-geographical schools were formed that exist today (Moscow, Leningrad (St. Petersburg), Voronezh, Irkutsk, etc.). Geographical education and practical research become impossible without mastering the theory and methods of landscape analysis and synthesis, mapping and zoning. This is what made the leadership of Tomsk State University (TSU), at the request of the Department of Geography, make a request to the Ministry of Higher Education for a postgraduate study at the Department of Physical Geography of Moscow State University, a graduate of the faculty, i.e. me, having a year of experience in the position of assistant, for targeted training in the field of landscape science. This direction was obtained, it only remained to appear in the capital and begin to study.

Key words: F. N. Milkov, landscape science.

Осень 1963 года ознаменовалась знаковым событием в истории ландшафтоведения - проведением в Алма-Ате VI Всесоюзного совещания, на которое прибыли почти все ведущие на тот момент ученые-ландшафтоведы. Участникам был представлен фундаментальный сборник докладов «Вопросы ландшафтоведения», проводилось ши-

() Булатов В.И., 2019 рокое обсуждение вопросов теории, методики, практики, имеющихся результатов. Проводились полевые экскурсии, были запланированы продолжительные выезды в прилегающие регионы Казахстана и Киргизии. Цель моей поездки была прежде всего в том, чтобы услышать и увидеть тех, кто активно разрабатывает теорию и практику ландшафтной географии, определяет ориентиры, на- 
чать постигать азы науки - в ТГУ ландшафтоведение не читалось, но естественно-научное образование было высоким и обеспечивалось такими учеными как Л. В. Шумилова, Л.Н. Ивановский, А. А. Земцов, М. В. Тронов, И. А. Вылцан, Н. В. Рутковская и другие.

Не буду перечислять всех участников Совещания - их имена давно вошли в историю физической географии, но отмечу элиту - Н. А. Гвоздецкий, А. Г. Исаченко, Н. А. Солнцев, Э. М. Мурзаев, К. И. Геренчук, В. С. Преображенский, В. И. Прокаев, Л. И. Мухина, А. А. Макунина, Н. И. Михайлов, Д. Д. Вышивкин, Б. Б. Прохоров, М. А. Глазовская, В. А. Николаев, В. М. Чупахин, Б. Б. Родоман и другие. Федор Николаевич представил доклад: «Типы местности как ландшафтные комплексы, их классификация и методы изучения».

Поскольку представители кафедры физгеографии МГУ находились в Алма-Ате, я решил обратиться к профессору Н. И. Михайлову, как наиболее вероятному научному руководителю, курирующему в МГУ Сибирь, автору вузовского учебника по Азиатской части СССР, когда мне прибыть в Москву и приступить к занятиям. Его ответ меня обескуражил: МГУ Минвузу не подчиняется и берет в аспирантуру тех, кого считает нужным, кто себя уже проявил в работе - при этом он указал мне на И.П. Чалую, которая была с другими сотрудниками МГУ и Алма-Аты соавтором статьи и ландшафтной карты по бассейну Б. Алмаатинки и бодро вела ландшафтную экскурсию (лет через 10 она стала кандидатом географических наук). Тогда я решил самостоятельно поискать себе руководителя и обратился к Федору Николаевичу, географу в научном мире известному, автору учебников, книг, по которым я учился. Федор Николаевич выслушал меня, спросил, есть ли у меня полевой опыт (у меня были только Алтай и Кавказ, изучение высокогорий и ледников). В Томске была сильная школа гляциоклиматологии, и я должен был стать аспирантом профессора М.В. Тронова, уже определившим мне объектом изучения ледники Белухи. Ф.Н. заметил, что горы - не его стихия, ландшафтная ниша на Алтае уже перекрыта диссертациями Г. С. Самойловой и Э. М. Раковской. Но у него есть целевое место в аспирантуру, на которое есть претендент, но человек ему неизвестный, из Минска. Я оставил ему на всякий случай свой адрес и отбыл на экскурсию на озеро Иссык-Куль.

Когда возвратился в Томск, меня уже ждала телеграмма из Воронежа с просьбой прибыть на собеседование. С ней я и направился к ректору ТГУ профессору А. И. Данилову, замечательному руководителю, инвалиду войны, будущему министру образования РСФСР. Немедленно был подготовлен приказ о командировке и я направился в Воронеж, куда и прибыл ранним утром, поселился в гостинице «Россия», которая оказалась рядом с домом Федора Николаевича и недалеко от корпуса ВГУ, где тогда размещался геофак. Первым человеком, которого я встретил на кафедре, был Анатолий Иванович Нестеров, поведавший мне по секрету, что накануне я уже был зачислен в целевую аспирантуру, и сказал, что меня ждет важная беседа с руководителем.

Беседа эта состоялась вскоре. Федор Николаевич спросил, как у меня с кандидатским минимумом (у меня были сданы иностранный язык и философия), но спецпредмет предстоит сдавать на кафедре. Затем зашел разговор о ландшафтных делах и тут я буквально поплыл - нужных знаний у меня, естественно, не было. Не стал он меня терзать, посмеялся, но я понял, что надо много работать. Предъявил ему бумагу от ТГУ с просьбой разрешить мне поработать еще семестр (нет замены) и начать обучение с 1 января 1964 года.

Этот семестр в Томске я посвятил изучению ландшафтной литературы, поэтому когда прибыл на учебу и снова беседовал с Федор Николаевичем, он заметил: «Вижу, вы времени зря не теряли». Это была высокая оценка: он вообще хвалил редко, а вот поругивал молодежь, критиковал коллег на кафедре частенько, был очень требовательным к себе и другим, не терпел расхлябанности, безответственности. Поэтому и на кафедре был порядок, атмосфера научности и высокой организованности [1]. Сотрудники его уважали и побаивались, а молодые ученики старались и работать, и учиться достойно.

Только теперь А.И. Нестеров, член комиссии по приему в аспирантуру, рассказал мне подоплеку моего зачисления. У приехавшего претендента из Минска были также сданы иняз и философия. Но на вопрос Ф.Н., чем бы он хотел заниматься, обучаясь на кафедре, последовал ответ, что его очень интересует движение материков (тогда много писали о гипотезе их дрейфа в духе Вегенера) и продемонстрировал массу вырезок из популярных изданий и газет. На вопрос, как он относится к ландшафтно-типологическому картографированию, знает ли о работах воронежских географов ответа не было. Из научных журналов по географии претендент назвал только «Географию в школе», ну и т.д. При этом, как вспоминал А. И. Не- 
стеров, Федор Николаевич понемногу багровел, что означало высокую степень недовольства. Он попросил претендента выйти и сказал комиссии, что такой аспирант его не устраивает, но есть один претендент из Сибири, с ним стоит попробовать, хотя сам Ф.Н. никогда в Сибири не бывал, по ее территории не работал. Так был решен вопрос о моем зачислении. История на этом сразу не закончилась, ибо была жалоба из Минска в министерство, но авторитет Ф. Н. Милькова был незыблем. Кроме того, как оказалось, проф. МГУ Н. И. Михайлов тоже был в курсе, он знал, что я прошусь в Воронеж и впоследствии стал моим оппонентом на защите кандидатской.

На кафедре в ту пору работали в разных должностях Тарасов Ф. В., Белосельская Г. А., Ежов И. Н., Бердникова 3. П., Ахтырцева Н. И., Дроздов К. А., Федотов В. И., Казарцева Л. П. (прекрасно оформлявшая графику всех публикаций кафедры) и другие. На факультете имелись квалифицированные картографы, гидрологи, экономико-географы, чья кафедра располагалась рядом, а аспирант моих лет проф. Ю.В. Поросенков много лет ее возглавлял. Приходили с соседних кафедр и приезжали гости - геоботаник С. В. Голицын, почвовед Б. П. Ахтырцев, гидролог В.М. Мишон, эконом-географ В.К. Ковылов, ученики Ф.Н. из других городов Н. И. Дудник из Тамбова, Ф. А. Максютов из Уфы, Г.Е. Гришанков из Симферополя, А. Абдулкасимов из Самарканда.

Пришло время определиться с темой диссертации, и Ф.Н. сказал мне - принесите план, что я и сделал, вымучив нечто, подобное плану курсовой работы по региону. Реакция руководителя была соответствующей, он посмотрел, усмехнулся и сказал - ну а теперь идите и пишите... Ясно, что этот детский лепет и близко не напоминал то, что получилось через два с половиной года упорной учебы, приобретения опыта написания разделов, статей, анализа материалов полевых исследований территории Томской области, которая становилась одним из главных полигонов нефтегазового освоения Западной Сибири. Сама по себе идея применения принципов ландшафтной типологии, разработанных в условиях лесостепной и степной зон Русской равнины, для Западной Сибири оказалась вполне диссертабильной, несмотря на различия в ландшафтной структуре, специфике лесоболотных ландшафтов, доминирующих в этой физико-географической стране.

Вся кафедральная и факультетская жизнь в Воронеже оказалась обучающей системой. Разра- ботка и обсуждение учебных программ, итогов практик, семинары на кафедре, представление статей в сборники, конференции с отчетами - все настраивало на деловой лад, жестко направлялось $Ф$. Н. От него доставалось и доцентам (помню жаркие дискуссии, например по вопросам выявления и морфологии городских ландшафтов с Ф.В. Тарасовым). Шло становление научной школы, а потому аспирантские работы контролировались достаточно жестко, проверялись полевые дневники, отчетные материалы, графика. Федор Николаевич включал аспирантов, как и других членов кафедры, во все научные мероприятия. Вспоминаю, например, как из Перми на кафедру для отзыва привез свою докторскую диссертацию «Физическая география Пермской области» будущей профессор Б. А. Чазов. Толстенный том был в доступе несколько дней и мы обязаны были с ним ознакомиться, подготовить замечания, выступать в обсуждении. И я осмелился тоже выступить, заметив, что предложенное название не годится - административные области понятия эфемерные, подверженные политическим веяниям, трансформациям (всем тогда было памятно переименование этой области из Молотовской снова в Пермскую) и предложил даже свой вариант. Федор Николаевич был доволен этим замечанием, и в итоге работа с названием «Физическая география Уральского Прикамья» была защищена Б. А. Чазовым в 1966 году.

Отношение ко мне Федора Николаевича было несколько иным, чем к тем, кто учился у него, слушал его лекции вживую, да и просто побаивался. Для меня стало очевидным - надо следовать негласному принципу Ф. Н.: «Делай, как я!». Личных бесед у нас практически не было: один раз посетили его дачу за городом, где вместо огородных культур к недоумению соседей росли деревья и кустарники.

На кафедре иногда он позволял себе рассказать что-нибудь из жизни своих коллег-ученых. Его рассказы о полевых исследованиях были совершенно замечательны, полевые дневники информативны, а главные данные, факты, мысли отражены в его географических работах. Я всегда жалел, что мне не удалось побывать с ним в поле, хотя многие аспиранты прошли эту школу. Не забуду его рассказ как он однажды в летний воскресный день на такси из Воронежа уехал посмотреть Саратовское Заволжье и далее Прикаспийскую полупустыню и оказался, как я теперь понимаю, на территории военного ракетно-космического поли- 
гона "Капустин Яр", где увидели такси, удивились, остановили машину и пригласили Ф.Н. в "320-е торговое управление". Сотрудники КГБ связались с Воронежем, с ректором ВГУ Б.И. Михантьевым, убедились, что профессор настоящий, в командировке, и отпустили с Богом - затевать скандал им было бы себе дороже - в годы холодной войны вдруг человек свободно проехал в секретную зону, да еще на такси - погоны бы полетели!

Воронежские коллеги охотно вводили нас, приезжих, в курс дела, в распорядок учебы и работы, было много непосредственной помощи иногородним аспирантам. В свою очередь все помогали коллегам из "братских" республик, например, узбеку А. Абдулкасимову из Самарканда, туркмену, эконом-географу Эрниязу Бердыеву из Ашхабада. Эта дружба, взаимодействие, сотворчество осталось на всю жизнь. Я, например, сформулировал А. Абдулкасимову, с которым у меня была совместная работа по Фергане, защищаемые положения в докторскую диссертацию, которую он успешно защитил в Баку в 1990-м году. Я специально спросил официального оппонента по диссертации В.М. Чупахина, хороши ли были защищаемые положения, и его ответ меня порадовал. Тогда была одна страна, единая география СССР.

На всю жизнь запомнилось мне празднование в Воронеже 20-летия Победы. Первое мая в 1965 году не отмечали из-за страшного ливня, но 9 мая прошла великолепная, по-настоящему праздничная, демонстрация - во главе которой были Герои Советского Союза, далее шли полные кавалеры Ордена Славы, в сохранившейся выцветшей солдатской форме, затем фронтовики с наградами, и далее все граждане - это был всенародный праздник! Вспомнил о своих родных, участниках Великой Отечественной: погибшего в марте 1945 года и похороненного в Германии дядю, отца, начавшего войну в битве под Москвой и прошедшего до Праги, другого дядю, умершего вскоре после войны от тяжелых ранений... Знаю, что защитивший в 1941 году кандидатскую диссертацию Ф. Н. имел бронь и за педагогическую деятельность в эти годы в 1945 году награжден медалью «За доблестный и самоотверженный труд в Великой Отечественной войне 1941-1945 гг.».

Конечно, мой переход на рельсы ландшафтной географии не был легким. Требовалось хорошее знание геологии, геоботаники, почв региона. Но выбора не было, надо было писать, печататься, выучить названия по латыни сотен растений, овладеть навыками геологической съемки, состав- лять ландшафтные карты, строить профили, ездить на научные совещания, благо билеты в общих вагонах были недороги. У меня была стипендия 65 рублей (с вычетом подоходного и налога на бездетность оставалось 61 руб. 12 коп, для получения 100-рублевой стипендии не было двухлетнего трудового стажа). Летом я подрабатывал на хоздоговорных работах с геологами в Томской области (съемка четвертичных отложений, гидрогеологическая съемка, отбор проб, аэровизуальные наблюдения), чему содействовал, учил и постоянно поддерживал меня зав. кафедрой географии ТГУ А. А. Земцов. Заодно получался доступ в важные фонды. Эти работы помогли понять основы ландшафтной индикации, а составленные мной ландшафтно-индикационные карты масштабов $1: 200000$ и $1: 50000$ на территории Томской, Новосибирской и Омской областей «живут» в этих фондах и за плату я могу снова их посмотреть. Во время учебы и полевых работ я всегда держал связь с Ф.Н., посылая ему письма из самых экзотических мест, иногда с засохшими комарами, и письма эти он приносил на кафедру и ставил меня, как рассказывают, в пример местным аспирантам.

Научиться писать также ясно, аргументированно, как Ф. Н., мечтал, наверное, каждый аспирант. Но не сразу сказка сказывается. С одной из первых статей «Опыт выделения типов местности в центральной части Томской области», подготовленной мной с Ю.И. Винокуровым, ныне д.г.н., профессором, бывшим директором Института водных и экологических проблем СО РАН, получился совершенно примечательный конфуз. Она попала в сборник трудов Конференции молодых географов Сибири «Научный поиск в современной географии» (Иркутск, 1966). Да вот только на обложке в названии сборника, который мне прислали, в слове «поиск» была пропущена буква О!

По своему научному складу и знаниям Федор Николаевич был энциклопедист, не случайно ему географические издательства доверяли создание учебников, словарей, энциклопедических изданий, классических монографий. При этом он никогда не забывал сделать ссылки на своих учеников, развить их идеи, что очень важно для начинающих географов. Им, помимо фундаментальных основ зональной физической географии, были разработаны основы теории антропогенной трансформации природы, высотной дифференциации и склоновой микрозональности равнинных ландшафтов, экологизации географии (экографии), парадинамического ландшафтно-бассейнового подхода и мно- 
гие другие. Его отношение к классикам географии, предшественникам-естествоиспытателям, поддержка их идей заслуживает особого внимания и изучения молодыми.

Обучаясь в аспирантуре, бывая на различных совещаниях, встречах я обратил внимание на то, как реагировали мои старшие коллеги, собеседники, известные ученые на мое сообщение, что я - ученик Ф.Н. Милькова. А их было немало: А. Г. Исаченко, Д. Л. Арманд, Ю. Г. Саушкин, В. Б. Сочава, В. С. Преображенский, П. Г. Шищенко, М. И. Нейштадт, А. И. Перельман... Подтвердилась правильность выражения: «Скажи мне, кто твой учитель, и я скажу - кто ты!». Авторитет Ф.Н. Милькова, как одного из лидеров в географии, был очевиден, а сам он говаривал, что самые острые научные дискуссии (например, с А. Г. Исаченко по содержанию антропогенного ландшафта) не отменяют доброжелательной переписки, уважительного отношения.

Мое обучение в Воронеже завершилось досрочной защитой диссертации в октябре 1966 года. Я покидал ВГУ, ставший моей второй школой, с большой благодарностью в сердце, а каждый приезд туда, особенно теперь, когда жизнь прожита, это праздник души. Федор Николаевич превратил меня из рядового выпускника провинциального вуза в географа-ландшафтоведа. Ландшафтный базис стал основой моих многолетних географических исследований в Западной Сибири - Томской, Новосибирской, Кемеровской, Омской областей и Алтайского края, севера Красноярского края, Северного Казахстана, а в последние годы и Ханты-Мансийского автономного округа Югры. И даже расширение поля моих научных интересов - в радиационную географию, военную геоэкологию, региональное и атомное природопользование, чему способствовало близкое знакомство и тесное сотрудничество с Н.Ф. Реймерсом, Ф. Р. Штильмарком, А. В. Яблоковым, идет от ландшафтоведения. Замечаю, что в преподавании я невольно копирую своего учителя, опираюсь на его подходы в передаче знаний, консультировании и научном руководстве аспирантами и докторантами: 7 моих кандидатов и 3 доктора наук (Д. В. Черных, Б.П. Ткачев, В.Т. Старожилов) - это тоже «птенцы гнезда Ф.Н. Милькова».

При работе в Сибири я не докучал Федору Николаевичу: редкие поздравительные открытки, приветы от общих знакомых, изредка приезды на конференции. Но при этом тщательно изучал все, что им написано. Однажды заметил, что во многих естественных науках, как сейчас говорят, на- уках о Земле, у людей, не являющихся географами, у специалистов-практиков, работающих далеко от Воронежа, ландшафтные идеи Ф.Н. устойчиво распространяются, живут своей жизнью, преломляясь с учетом региональной специфики. Территориально они особенно заметны в Западной Сибири, в Якутии, на Урале, на Дальнем Востоке, их распространение связано как с деятельностью учеников Ф.Н. - В.В. Козина, А.А. Чибилева, Ю. Г. Данилова, В. С. Хромых, так и с их доступностью, простотой, логичностью, картографичностью, возможностью независимой проверки, т.е. всем тем, что можно назвать практической необходимостью, жизнеспособностью, востребованностью.

Последняя встреча с Учителем была у меня перед защитой докторской диссертации в Институте географии СО РАН в Иркутске. Я приехал за отзывом в Воронеж и очень хотел повидать Ф.Н. Отзыв весьма положительный я получил, короткая встреча состоялась. Чувствовалось, что Федору Николаевичу нездоровится, но он нашел те слова, которые нужны были мне в столь ответственный момент. Провожая, сказал на лестнице - «Эх, сбросить бы годков 15, поработать еще». Защита моя прошла успешно, о чем я сообщил в Воронеж. А вскоре пришло письмо: «Воронеж, 1 ноября 1996 г. Глубокоуважаемый Валерий Иванович! Сердечно поздравляем Вас с успешной защитой! К сожалению, Федор Николаевич уже не сможет разделить с нами эту радость - 15 октября его не стало. С уважением А. Бережной».

Со дня кончины профессора Ф.Н. Милькова прошло почти четверть века, но внимание к его биографии и научному творчеству продолжается $[1,2]$.

Полезно перечитывать классиков, помнить их заветы. Помню совет Ф. Н. не публиковаться, если нет новых мыслей, но если они есть - обязательно записать, обдумать, предложить научному сообществу. К примеру, модернизируя представления о ландшафтной сфере в развитие его идей мной были высказаны соображения о континентальноокеанической дихотомии, необходимости выделения и обоснования, включения в научный анализ таких фундаментальных свойств ландшафтной сферы как мерзлотность и радиоактивность, о чем было сообщено в последних публикациях в Воронеже. Еще одна тенденция, заметная в последние годы в ландшафтоведении - сближение подходов различных школ, направлений. Здесь есть и не очень удачный опыт, когда на примере ландшафтного картографирования севера Западной Сибири 
пытались совместить подходы ландшафтно-динамической школы иркутских географов (В.С. Михеев) и воронежской школы ландшафтного анализа (В. В. Козин). Их совместная экспедиционная работа, дискуссии, обильные возлияния не завершились созданием единой территориальной ландшафтно-картографической модели, подтвердив известное выражение: «В одну упряжку впрячь не можно коня и трепетную лань». Видимо правы китайцы, утверждающие «пусть процветают сто школ, пусть расцветают сто цветов». А современный взгляд на ситуацию с ландшафтоведением представлен в сборнике РГО «Горизонты ландшафтоведения». Вопросы географии. № 138. - М., 2014. Это одна из тех научных географических серий, в которых Ф.Н. Мильков нередко публиковался, подавая пример ответственного и продуктивного научного творчества. И, конечно, достойным памяти Учителя было проведение в Воронеже в мае 2018 года конференции, посвященной 100 -летию со дня его рождения.

Булатов Валерий Иванович доктор географических наук, профессор кафедры экологии и природопользования Югорского государственного университета, г. Ханты-Мансийск, E-mail: vibul@rambler.ru

\section{СПИСОК ЛИТЕРАТУРЫ}

1. Михно В. Б. День памяти 4. Выдающийся географ-ландшафтовед (к 100-летию Федора Николаевича Милькова) / В. Б. Михно, В. И. Федотов // Вестник Воронежского государственного университета. Сер. География. Геоэкология. - 2018. - № 1. - С. 112-127.

2. Федотов В. И. Профессор Ф. Н. Мильков. Место рождения. Родословная / В. И. Федотов, С. В. Федотов // Вестник Воронежского государственного университета. Сер. География. Геоэкология. - 2019. - № 2. C. 110-113.

\section{REFERENCES}

1. Mikhno V. B. Den' pamyati 4. Vydayushchiysya geograf-landshaftoved (k 100-letiyu Fedora Nikolaevicha Mil'kova) / V. B. Mikhno, V. I. Fedotov // Vestnik Voronezhskogo gosudarstvennogo universiteta. Ser. Geografiya. Geoekologiya. - 2018. - № 1. - S. 112-127.

2. Fedotov V. I. Professor F. N. Mil'kov. Mesto rozhdeniya. Rodoslovnaya / V. I. Fedotov, S. V. Fedotov // Vestnik Voronezhskogo gosudarstvennogo universiteta. Ser. Geografiya. Geoekologiya. - 2019. - № 2. - S. 110-113.

Bulatov Valery Ivanovich

Doctor of Geographical Sciences, Professor of the Department of Ecology and Nature Management, Ugra State University, Khanty-Mansiysk, E-mail: vibul@ rambler.ru 